\title{
...MOVIMIENTOS EN EL 'MOVIMIENTO'. REFLEXIVIDAD Y PERFORMANCE DE UNA PRESENCIA AFRODESCENDIENTE EN ARICA (CHILE)
}

\author{
...MOVEMENTS IN THE 'MOVEMENT'. REFLEXIVITY AND PERFORMANCE \\ OF AN AFRODESCENDANT PRESENCE IN ARICA (CHILE)
}

Mariana LEón VILLAGraA

El artículo aborda la emergencia afrodescendiente en Arica, Chile, desde la dimensión sensible, creativa y reflexiva de la performance del Tumbe carnaval y el nacimiento de la primera comparsa afroariqueña. Frente a una visión tendiente a encapsular el Tumbe carnaval como auxiliar al movimiento etnopolítico, se propone que esta performance con 'sus movimientos' imprime una capacidad sensitiva que invoca sentidos y memorias abriendo campo a procesos cognitivos sustanciales para el auto-reconcimiento afrodescendiente. Así, desde la perspectiva de la performance, busca sostener que el pensar-sentir enraizado en la experiencia corporal del Tumbe carnaval es contestaria, reflexiva y constitutiva del renacimiento cultural afrochileno y la expansión del Movimiento etnopolítico afrodescendiente en Arica.

Palabras clave: Afrolatinoamericanos, Afro-chilenos, Performance, Memoria corporal, Tumbe carnaval.

This article delves into the emergence of afro-descendant presence in Arica (Chile) from the sensitive, creative and reflective dimensions of the performance of the Tumbe Carnaval and the beginnings of the first Afroariqueña troupe. Confronting the view that has tended to encapsulate the Tumbe Carnaval as an aid to the ethno-political movement, the article suggests that this performance with its 'movements' imprints a sensitive ability to the body that calls upon senses and memories opening the way to key cognitive processes for afro-descendant self-recognition, and where the action of think-feel, rooted in the experience of Tumbe Carnaval, is reflective and generative of the afro-Chilean cultural revival and the expansion of the ethno-political afro-descendant movement in Arica.

Keywords: Afro-Latino, Afro-Chileans, Performance, Body memory, Tumbe Carnaval.
Nosotros también, porque a veces somos ¡apuntados! "porque solo bailamos, y no nos

pareciera que nada más fuera importante", y la verdad que no es así, porque nosotros desde el baile y desde el ritmo, ¡vamos apuntando

a lo mismo!, que es en el fondo el reconocimiento sociocultural de los afrodescendientes en Chile, y ese es el "gran objetivo" (Carolina Letelier Salgado, entrevista personal, Arica 7 de febrero de 2013).

\section{INTRODUCCCIÓN}

Atardecía el 5 de enero del 2003. En el paseo peatonal 21 de Mayo se abrió paso un pequeño grupo de personas que, con sonidos, ritmos y movimientos, trastocaría la vida sociocultural de Arica -y de paso la de Chile-. Eran casi treinta personas de la naciente comunidad afrochilena que llevaban un año trabajando para la ocasión. Estaban todos expectantes; las mujeres usaban "faldas floriadas, compradas en una tienda hindú”, dijo Marta Salgado, "que tan solo nos costaron como mil pesos". Los hombres templaron los cueros de tambores creados y construidos para la ocasión, y ¡retumbó el tumbe!, en un pasacalle por el centro histórico de la ciudad. La Estrella de Arica1 tituló "Donde los tambores resuenan

A Mariana León Villagra, Facultad de Ciencias Sociales, Universidad de Chile, Chile. ORCID: 0000-0002-1731-5792.

E-mail: marianaleonv@gmail.com 
en la piel. Detalles de la desconocida historia 'negra' del extremo norte de Chile". Era la "primera salida" de la comparsa afroariqueña, una acción político-artística para conmemorar la Pascua de Negros y decir "iaquí estamos, hay afrodescendientes en Chile!", e iniciar la lucha por el reconocimiento sociocultural afrodescendiente (Letelier 2015, Salgado 2015). ${ }^{2}$

Después de una década, el acto de transitar por la ciudad invita a pensar que ese pasacalle y su continuidad de pasos y coreografías, movimientos y desplazamientos de las actuales comparsas afroariqueñas, ${ }^{3}$ fue una acción reflexiva y generativa de una presencia afrodescendiente en Arica. La performance del Tumbe carnaval -dimensión narrativa-, bajo su unidad organizada en comparsa -dimensión colectiva- (León 2017: 124), permitió un proceso importante: transitar del 'pre-ser' al 'ser', o, de ser 'ariqueño promedio' a ser afroariqueño, con sus desdoblamientos: afro, afrodescendiente, moreno, negro, afrochileno, etc., (León 2016, 2017). En un tránsito donde el cuerpo se torna un encuentro teórico-práctico para pensar desde el movimiento (Bardet 2015).

La emergencia de la comunidad afrodescendiente en Arica (Chile) ha sido tratada como proceso etnopolítico e identitario (Mora 2011, Espinosa 2013, Ducongé 2015) desde riberas teóricas diversas, centrándose en aspectos textuales y discursivos y enfocándose en la relación con el Estado. Esto reduce la expresividad de las comparsas y del baile tumbe carnaval a una práctica cultural auxiliar a la configuración étnico-identitaria "afro" y al Movimiento político-cultural por el reconocimiento de los Afrodescendientes, llamado el "Movimiento". Pero es posible proponer que, por el contrario, el Tumbe carnaval ha sido capital para la 'identidad' afro y sinérgico para el "Movimiento" político; no es secundario o auxiliar, sino constitutivo.

En mi etnografía analicé dicha emergencia afrodescendiente desde otra ribera: la de la experiencia y los sentidos, donde el nacimiento de la primera comparsa y el Tumbe carnaval es tratado como performance (León 2016, 2017). Siguiendo la propuesta de Seeger (2015a), que estudia la vida social como performance, en vez de presuponer una matriz social y cultural pre-existente (antecedente) donde "examina a maneira como a música faz parte da própria construção e interpretação das relações e dos processos sociais e conceituais" (Seeger, 2015a:1415), y que la performance musical es generativa de la vida social (Blacking 2007, Seeger 2015a). A partir de Blacking, observo cómo ciertos aspectos de la vida social son productos del pensamiento musical (Blacking 2007: 208), pues la cognición artística es una fuente importante para la vida humana y la praxis artística puede influenciar e iniciar una acción social (Blacking 2007, 2013).

Como parte de mi etnografía, desde 2012 a 2016 me he relacionado con los agentes creativos que participaron en la creación de la primera comparsa, en ámbitos sonoros y coreográficos (León 2014, 2016, 2017). Para el análisis de los "pasos" del tumbe, consideraré la opinión de Carolina Letelier Salgado, una de las creadoras de dichas coreografías, a lo que sumo observaciones etnográficas y opiniones de tumberos y tumberas. Pretendo, además, delinear esta metáfora: "Movimientos en el Movimiento". En este sentido, propongo que la conformación de la primera comparsa y la performance del Tumbe carnaval, como "movimientos" danzados al centro del "Movimiento" etnopolítico afrochileno, sobrepasó su ámbito inicial. Por su capacidad sensible, creativa y reflexiva, permitió transmitir saberes y memorias de

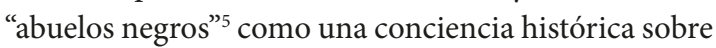
su presencia en el territorio.

En este artículo, primero se presenta un breve contexto histórico de la colectividad. Luego, una reseña del "Movimiento", como una acción cultural para reivindicarse, que denomino "renacimiento cultural" afrochileno, y que recrea el Tumbe carnaval. Tercero, un análisis sobre la performance, en torno a los "pasos" del Tumbe. ${ }^{6}$ Desde ahí, pretendo reflexionar sobre la acción de pensar y sentir desde el movimiento (Blacking 2013, Buckland 2013), asumiendo la perspectiva teórica de la performance, y dialogando con autores que tratan la memoria corporal como modo de conocimiento (Jackson 2010, Taylor 2011). Pues el Tumbe, al ser una experiencia musical contrastaste (Blacking 2007, 2013) alojada en el cuerpo, transformó vidas y construyó un espacio, o universo comunicativo común, que posibilitó autorreconocerse como afrodescendiente, dado fuerza sustantiva al movimiento político afrochileno.

Conviene aproximar al lector a las multiplicidades del Tumbe carnaval. "Tumba", "tumbe" o "tumba carnaval" es un baile de carnaval rescatado desde la memoria oral. Su característica era el movimiento de caderas, conformando una rueda, donde la mujer, con juguetona destreza, botaba al compañero con un jsevero caderazo! (Báez 2010). Su imagen, desde la memoria, también evoca fiestas y jolgorios familiares en época de carnaval, baile compitiendo entre grupos bajo árboles que cobijaban con su sombra veraniega la fiesta rural. 
Se sabe que había bloques (grupos) de negros que bailaban/sonorizaban el tumbe en la ciudad, que habrían desaparecido, dejando recuerdos vagos. Es importante aclarar que cuando la comunidad reconstruyó esas memorias, no existía un cuerpo de músicos y bailarinas ejecutantes (como continuadores de una tradición) como comparsa. Se (re)construyó más bien a base de memorias de golpes, tarareos, gestualidades y expresiones que personas mayores pudieron relatar. Por ello, conformar una comparsa, trayendo a la vida el Tumbe carnaval, es una decisión colectiva de la comunidad y sus nuevas generaciones (años 2002-2003).

Entre quienes participaron de la conformación de la comparsa hay plena conciencia de que es un baile/ ritmo "recreado", siendo controversial el uso de "tumbe" o "tumba", sin llegar a un acuerdo. Algunos indican que "tumbe" se refiere a la expresión recreada del antiguo "tumba". También hay consenso de que no existían tambores (como los actuales), sino materialidades espontáneas (barriles, cajas, etc.) que eran percutidas para sonorizar y, solo a veces, se usaban bombo andino y guitarra para las coplas (León 2017).

En la actualidad, hablar de Tumbe carnaval refiere principalmente a una expresión rítmica, sonora, coreográfica y cantada en formato de comparsa para desfile de carnaval. Aunque, como acto performático, también se ejecuta en otros espacios de la comunidad afrodescendiente (velorios, celebraciones de la Cruz de Mayo, etc.) que no formaban parte de su tradición; antes era solo un baile de carnaval. La batería rítmica del actual tumbe carnaval es $4 / 4$, compuesta por dos tambores (bombo y repique) cencerro, güiros y chequerés. Tiene similitudes con el festejo peruano, pero difiere por bailarse en comparsa, el tiempo fuerte en el 2, donde el bombo hace los graves, los repiques el agudo, el güiro/chequeré los tresillos y el cencerro va uniendo todo (la clave).

En términos cinéticos, su eje es el movimiento de caderas y lo expresa la misma raíz de su nombre tumbe (de tumbar). Su nombre tiene una correspondencia motora o de movimiento y su foco alude a moverse asociado a un gesto marcado en la coreografía del baile y al grito ¡tumba carnaval! En términos de comparsa, la coreográfica inicial (que se recreó en 2003) ha tenido innumerables modificaciones, en términos etnográficos solo se ha observado el formato de las comparsas actuales, compuesta por bloques de bailarinas y bailarinas en líneas de cuatro personas.
Además, las comparsas hacen uso de la palabra tumba para un universo más amplio que lo rítmico. Así las niñas son las "tumberitas" y a los músicos y músicas se les denomina "tumberos", pues viven el tumbe o son parte de ese universo simbólico. En el desfile de carnaval, las individualidades se desvanecen y el tumbe emerge como un "ser vivo" que resuena en las calles y abraza la ciudad; nadie podría negar que se levanta y grita.

\section{Apuntes de un espacio "histórico"}

Para movernos necesitamos un piso, ese punto del mapa donde nace el tumbe carnaval en la Región de Arica y Parinacota, límite entre Chile, Perú y Bolivia. Sus trazos son dúctiles, el puerto de Arica (fundado en 1570) fue parte del Virreinato del Perú, siendo la principal salida del mineral de Potosí. Posteriormente, integró parte del Perú republicano (1821-1883) que, tras la Guerra del Pacífico (1879-1883) pasó a ser del Estado de Chile, sufriendo un proceso de anexión: la chilenización (1883-1929).

En dicho "espacio", como cúmulo de historias (Massey 2005: 183), el colonizador español instaló población esclava africana para la producción agrícola (Briones 2004, Díaz et. al 2013, Díaz 2015, Ducongé 2015). El interés económico por la explotación mineral fue un detonante para el ingreso de esclavos africanos a los Andes desde el siglo XvII, aunque mayormente para la explotación agrícola, bajo el sistema de plantaciones en la costa pacífica (Cuché 1975, Ducongé 2015), y en menor medida, para servicio doméstico. La región de Arica proveía de alimentos a Potosí, dada la demanda por la explotación mineral, aunque, a diferencia del resto del Perú, no habría existido la gran hacienda colonial sino pequeñas unidades de producción (Briones 2004: 816); y, si bien hubo mano de obra indígena, fue mayoritariamente negra. Los españoles organizaron varias haciendas con esclavos africanos, y a través de un sistema de compraventa se fueron fragmentando las extensiones de tierras de indios (Díaz 2015: 768). Luego de un brote de malaria y por otras situaciones sociales, muchos españoles-criollos migraron a distintas ciudades del Perú, dejando sus tierras al cuidado de estos agricultores negros (Díaz 2015). Para la historiografía esto explica cómo los esclavos negros lograron su libertad y ser propietarios de esos terrenos.

El sistema colonial reconfiguró el territorio: ${ }^{7}$ la población indígena se replegó en la precordillera y 
el altiplano, mientras los esclavos negros se ubicaron en los valles productivos y el puerto, llegando a ser mayoría. En las primeras décadas del siglo XviI son el 73\% de la población en Arica (Díaz et al. 2013: 56), situación que se mantiene en el período republicano: en el censo de 1871 se señala que los negros y mestizos negros constituían el 58\% de la población de la ciudad (Wormald 1966 [1903]: 161). Por tanto, la población negra era numerosa iniciada la guerra.

Si la explotación minera fue uno de los motores para el tráfico negrero en el Pacífico y su empleo en la producción agrícola, la codicia por el salitre -también con intervención de potencias, como Inglaterra- motivó la Guerra del Pacífico (1879-1883). Tras el fin de las campañas bélicas (1883), las provincias peruanas de Tacna y Arica quedaron bajo dominio temporal chileno en miras de realizar un plebiscito que decidiría su destino, lo que nunca ocurrió. Finalmente, con un acuerdo diplomático (1929), Tacna pasó a soberanía peruana y Arica a Chile. En ese período, llamado chilenización, el Estado chileno ejerció control social y simbólico persiguiendo cualquier elemento tildado de "peruano", buscando asegurar la hegemonía nacional (González 2008, Díaz 2014). Este asedio fue catalogado de nacionalista por la historiografía decimonónica (Morong 2014), pero fue evidentemente xenófobo: la población era mayoritariamente negra (Artal 2012, Ruz 2013, Ducongé 2015) y también se persiguió al cholo o indígena (Soto et al. 2014). Los antiguos negros fueron hostigados, marcaron sus casas, quemaron sus negocios, fueron asesinados y otros huyeron, desintegrándose las familias (Báez 2010, Artal 2012, Espinosa 2013). Los ojos que vieron (vivieron) esa violencia fueron los "abuelos negros" de mis entrevistados, quienes recordaron estos hechos décadas después.

Con una mirada etnográfica propuse analizar este proceso siguiendo a Sahlins (2004), puesto que la trata negrera, la explotación agrícola y el flujo del puerto, vinculado al comercio en Potosí colonial, y la disputa republicana por el salitre, son dos caras del impacto de sistemas coloniales - con distinciones y períodos diferentes-, y parte del capitalismo mundial (León 2017: 39-40). Los Estados coloniales se vincularon con la población dominada a través de técnicas de represión, modificando las condiciones de "reproducción cultural" (Sahlins 2004: 524). No obstante, aun bajo esas condiciones, los pueblos crean sus vidas; aunque tuvieron que borrarse como negros, chilenizarse, ellos no olvidaron (Artal 2012). Se pueden estudiar las modalidades de cambio frente al impacto del capitalismo mundial, donde los pueblos a través de la inventiva de sus tradiciones desafían la Historia (Sahlins 2004).

\section{Reseñas del 'Movimiento' etnopolítico y el renacimiento cultural afrochileno}

Entre los años 2000 y 2003 una historia de encuentros confluye en la oNG Oro Negro. El año 2000, Sonia y Marta Salgado asistiernn a la Jornada Regional Conferencia +5 en Santiago (Chile), actividad preparatoria para la III Conferencia Mundial Contra el Racismo organizada por la ONU. ${ }^{8} \mathrm{~A}$ esta última, realizada el 2001 en Durban (Sudáfrica), también asistieron (Salgado 2010, 2015). En la Conferencia +5 se proclamaron como afrochilenas y forman Oro Negro, en torno a la familia Salgado. Dicho hito (re)moverá memorias, uniendo otros troncos familiares que posteriormente originarán nuevas colectividades (León 2017, Ducongé 2015, Espinosa 2013, Mora 2011). Aunque existía una conciencia previa al uso político de la nominación afrodescendiente, como cuenta Marta:

\begin{abstract}
en conversaciones con mi mamá, ella [Sonia Salgado] le preguntó por qué ella tenía ese pelo motito, entonces mi mamá le dijo "no le vas a contar a nadie, pero nosotros descendemos de esclavos africanos". Y entonces empieza ahí toda una historia, que ella conversa conmigo. Empezamos a armar la organización, y esta organización se arma al alero de la familia Salgado, Salgado Henríquez, Salgado Cano, Henríquez Corvacho, Vildósola Corvacho, y entonces es todo un tronco familiar donde nace esta ONG (Marta Salgado, entrevista personal, 30-01-2012).
\end{abstract}

Era un grupo pequeño "muy familiar", recuerda Gustavo del Canto, periodista que viaja a Arica (2001) para hacer un reportaje sobre los "afro". Él, apoyado por Sonia, empieza a entrevistar y fotografiar a distintas familias. El gesto de entrar en casas y remover historias gatilló el entusiasmo por rescatar memorias que la chilenización había apagado, congregando a las familias negras para reconstruir tradiciones y escenificarse en un presente, ahora como afrochilenos (León 2016, 2017). Con ese "rescate" -como ellos lo llaman- sistematizan conocimientos sobre su presencia en el territorio, reflejándose en publicaciones de la comunidad (Del Canto 2003, Báez 2010, Salgado 2010, 2013), que posteriormente registra la institucionalidad cultural. ${ }^{10}$ Desde la acción cultural conquistaron espacios como el estudio específico realizado por el INE (2014) y su reciente reconocimiento con la Ley 21.151 del Congreso Nacional (2019). ${ }^{11}$ 
En ese primer momento, la memoria oral menciona el baile y la fiesta en fecha de carnaval, llamado "tumba" o "tumba carnaval", que habría perdurado mayormente en un ambiente rural (Del Canto 2003, Báez, 2010, Salgado 2013, Letelier 2015). Pero, "memoria" no es solo acoger una imagen del pasado, es también ejercerla, hacer algo con ella (Ricoeur 2004: 81). Ese relato "recordado" se vuelve crucial: la colectividad decide darle vida, organizarse para formar una comparsa urbana contemporánea y "recrear" el tumbe, saliendo por primera vez en Pascua de Negros, en 2003 (León 2017: 66-78). Pero esta comparsa rápidamente desbordó la función de ocupar la calle para el movimiento político: la performance del Tumbe carnaval fue vital, pues conformó comunidad, atrajo personas e hizo visible la presencia afroariqueña no solo en Arica, ${ }^{12}$ sino a nivel nacional e internacional. ${ }^{13}$

Sin duda el Movimiento tomó una opción cultural para su reivindicación. A través de la recreación de sus tradiciones conformó comunidad y levantó un espacio existencial en torno a la memoria agrícola. El hecho de rescatar su memoria frente al "borrón" provocado por la chilenización, fue conceptualizada de manera positiva y creativa, proceso que llamo "renacimiento cultural afrochileno", siguiendo el análisis de Sahlins (2004).

Hay voces que califican el Tumbe carnaval como una ficción musical, que tomó elementos foráneos -del candombe, batucadas, festejo-, y no representa una auténtica tradición (chilena), sino que corresponde a una moda. Son discursos apegados a una visión romántica de la tradición, como esencia que reproduce un pasado inmutable. Pero, desde una perspectiva etnográfica que simetrice las relaciones (Goldman 2008), es pertinente equiparar "ficciones", recordando que, la instauración en Arica de nombres de calles, hitos y festividades alusivas a próceres patrios, con la chilenización, también es una tradición inventada para establecer una continuidad con un pasado histórico (Hobsbawm 2006: 9), o "acorde" al ideal nacional chileno. Además, hay que considerar que "a 'tradição' aparece muitas vezes na história moderna como uma modalidade culturalmente especifica de mudança" (Sahlins 2004: 508), como un modo que tienen los pueblos para enfrentar el impacto de sistemas coloniales, para el control de su reproductividad cultural. No es fortuito que en las narrativas emerja la chilenización como "un antes y un después". El "renacimiento" cultural afrochileno es una toma de conciencia histórica sobre la chilenización, que sirve para controlar relaciones con la sociedad dominante -la chilena- que no reconocía ni

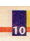
Donde los tambores
resuenan en la piel
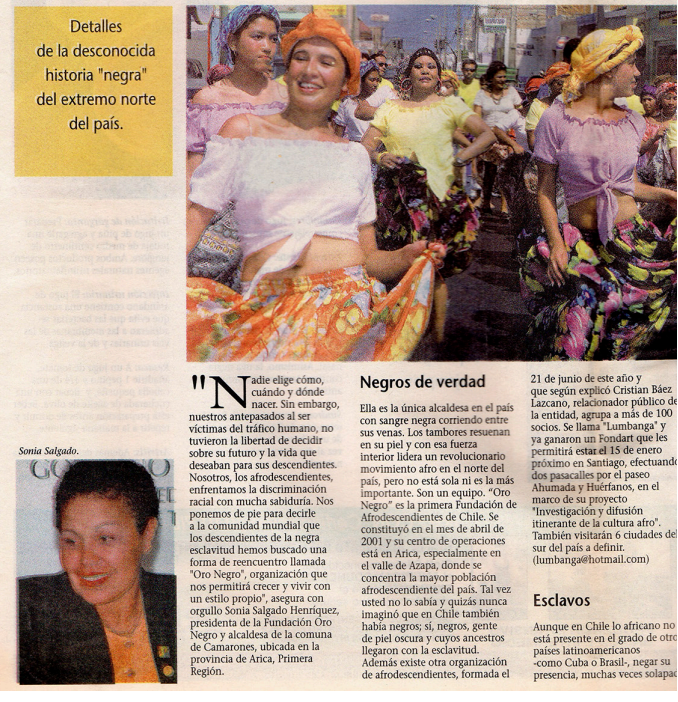

Figura 1. Recorte de prensa sobre la primera salida de la comparsa del Tumbe carnaval. (Fotografía: La Estrella de Arica, 6 enero 2003. Proporcionado por Dino Toledo). Figure 1. News clipping about the first outing of the Tumbe carnaval troupe. (Photograph: La Estrella de Arica, January 6, 2003. Provided by Dino Toledo).

su pasado, como negros, ni su presente, como afrodescendientes. Así, la "recreación" del Tumbe carnaval es paradigmática: es la invención de una "tradición", una modalidad culturalmente específica de cambio (León 2017: 76), vinculando pasado y presente, aludiendo a la dimensión agrícola y de larga duración.

El corpus de tradiciones, una teoría nativa sobre su presencia, apela al ciclo agrícola festivo: Carnaval, Cruces de Mayo, San Juan, San Miguel y otras fiestas patronales de los Andes. La oralidad desentierra prácticas agrícolas: cultivo de la caña de azúcar, hortalizas, algodón, vino y sobre todo el cuidado del olivo, y apunta a oficios y objetos de un saber-hacer tradicional: el cortador de caña, la algodonera, el tonelero, la raima o cosecha de aceituna, las combas para recolectar aceituna o algodón, a las negras verduleras descendiendo en burro para vender en la ciudad (Báez 2010). Todas ellas son expresiones de un universo agrícola, pues los esclavos negros en los Andes llegaron a producir la tierra para un otro: el español, y fueron los primeros en manejar los cultivos foráneos 


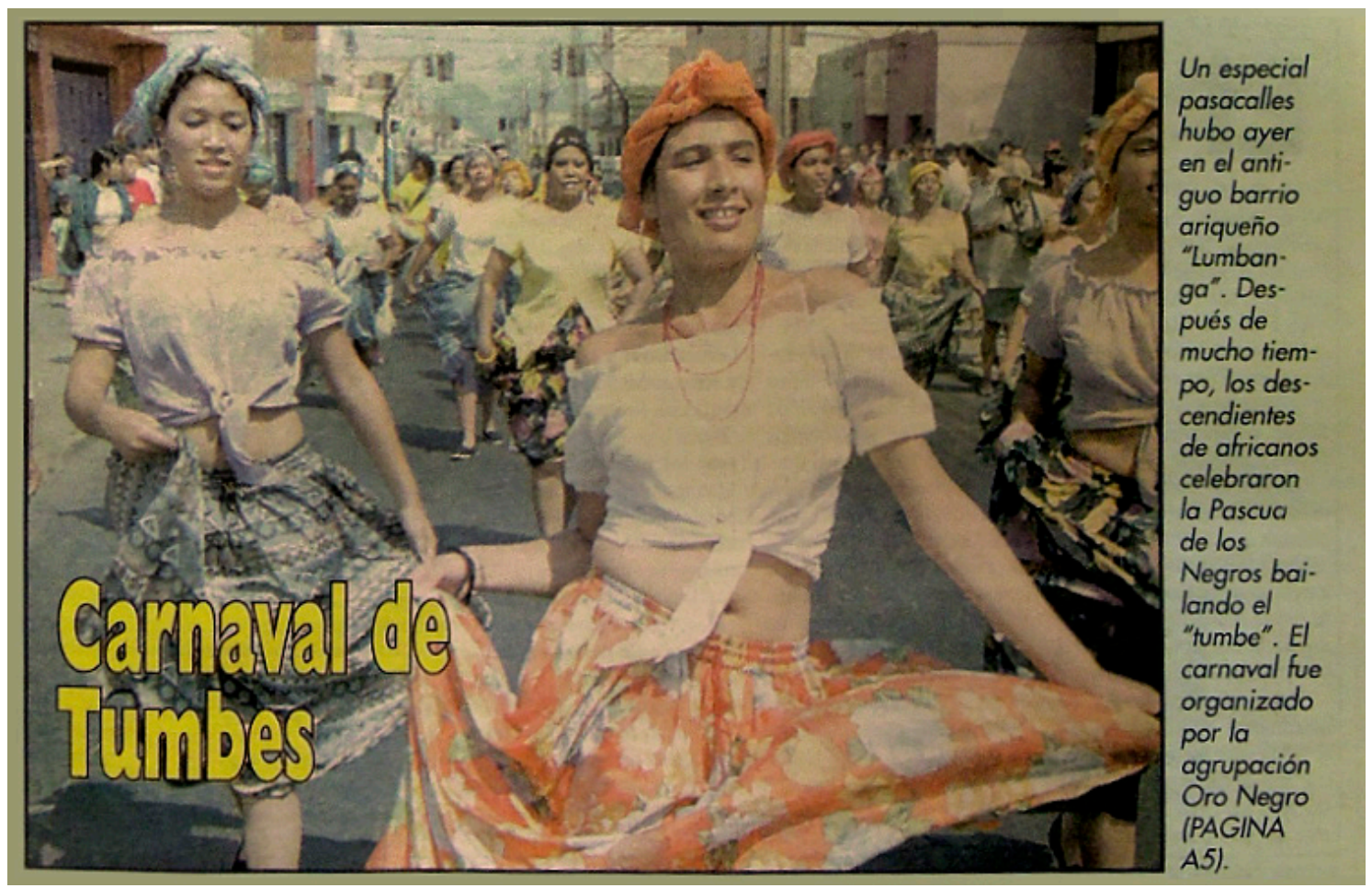

Figura 2. Foto de la primera comparsa en sus primeros años. (Fotografía: La Estrella de Arica, 2003). Figure 2. Photo of the first troupe in its early years. (Photograph: La Estrella de Arica, 2003).

(Celestino 2004: 30). Pero esos negros que -aunque a la fuerza- habitaron este lugar, con el tiempo se unieron a la tierra y permanecieron cultivándola.

Desde una visión nativa, son esas labores agrícolas -y no la ausencia de españoles- las que explican cómo los descendientes de africanos lograron su libertad y ser dueños de sus terrenos:

$$
\begin{aligned}
& \text { Los productores directos y encargados de la buena cosecha, } \\
& \text { tanto de la caña de azúcar, el algodón, el camote, el olivo, la } \\
& \text { misma vid y otras pequeñas hortalizas, eran los africanos } \\
& \text { esclavizados en sus orígenes y sus descendientes, entonces, } \\
& \text { ahí podemos darnos cuenta de que la capacidad intelectual } \\
& \text { y comercial fue clave para las producciones y posterior } \\
& \text { independencia" (Báez 2010: 24). }
\end{aligned}
$$

El renacimiento cultural afrochileno releva esa memoria agrícola como epicentro de su presencia en el territorio y también como un modo de conocimiento desde el hacer. Se aleja de una visión burguesa de cultura idealista que niega los aspectos físicos del ser, construyendo una separación mente/cuerpo, donde incluso la idea de cuerpo ha sido dominada por la mente (Jackson 2010, Blacking 2013). Eso rescata el sentido original de la palabra cultura, una actividad práctica, en el ambiente, hecha por seres humanos: "cultivar la tierra antes que cultivar la mente" (Jackson 2010: 61), siendo la práctica corporal la base de todo proceso de conocimiento. Jackson propone que existe un conocimiento corporal -cuyos sentidos son previos al lenguaje y no reducibles a significados semánticos-, retomando el "cuerpo vivido" de Merleau-Ponty, en el cual el sujeto es necesariamente un sujeto corporizado (Jackson 2010: 60).

Desde aquí comprendo que la memoria agrícola, que el renacimiento afrochileno sistematizó con el Movimiento etnopolítico, es una conciencia cultural del pasado y el presente, cuyas tradiciones revelan la continuidad de prácticas y saberes vinculados a un espacio y a un modo de comprender el mundo desde el hacer. El universo agrícola es "el entorno de un modo de actuar" -indica Jackson siguiendo a Wittgenstein-, pues la experiencia humana está asentada en movimientos corporales en el ambiente social y material, produciendo interacciones entre patrones habituales del uso del cuerpo e ideas convencionales sobre el mundo (Jackson 2010: 68). En este caso, se trata de la continui- 
dad en un entorno agrícola de los esclavos africanos/ agricultores-negros/afrodescendientes-danzantes.

\section{La performance del Tumbe carnaval... Labores agrícolas escenificadas}

El viento golpea playa Corazones. Converso con Carolina Letelier Salgado sobre el tumbe, y me cuenta cómo fue rescatar este baile desde "el oír" a los abuelos:

Ellos nos contaron un poco sobre [...] las antiguas prácticas de los negros en Arica y en el Valle de Azapa, las prácticas eh [...] asociadas al baile, a los ritmos. Dentro de todo lo que se investigó llegamos a un punto de similitud entre todas las cosas que nos dijeron [...] que tenía que ver con el tema de bailes carnavalescos, de fiesta, asociados al movimiento de cadera, de tumbarse y de botarse; principalmente eso como eje fundamental de lo que es el tumbe o la tumba (Carolina Letelier, entrevista personal, 07-02-2013).

Como se indicó anteriormente, los textos de la misma comunidad describen el tumbe de antaño como un baile ejecutado en carnaval, caracterizado por el movimiento de caderas, el coqueteo entre las parejas, el formato de ronda y el caderazo al grito de "ituuumba carnaval!" (Del Canto 2003, Báez 2010, Salgado 2013). Aunque se hacía en la ciudad, el recuerdo más vívido permaneció en el contexto rural y familiar, espacio protegido ante la chilenización. Los movimientos recreados se basaron en la cadera y la disposición espacial de la rueda, pero urdiendo "pasos" creados para dar cuerpo (forma) a la primera comparsa:

Lo que nosotros hicimos con el tumbe, fue tomar estos pasos de cadera que nos dijeron y sobre lo mismo empezar a recrear, con pasos que estuvieran asociados a las actividades laborales que tenían los afrodescendientes en el valle de Azapa, como por ejemplo, el corte de la caña, que nosotros hacemos un paso que tiene que ver con el machete; la raima de la aceituna, nosotros cuando hacemos ese paso simulamos que tenemos una comba, entonces raimamos; obviamente que la raima de la aceituna no es así originalmente, cuando la gente raima no está bailando [...] pero nosotros tomamos eso e hicimos una recreación sobre eso, tratamos de poner esa práctica dentro de lo que es un ritmo, que es el tumbe (Carolina Letelier, entrevista personal, 07-02-2013).

Los primeros pasos de la recreación fueron el machete, asociado a la cosecha de caña; el paso de la aceituna, de la raima, y el paso algodón, asociado a sus cosechas; el paso base (a veces llamado de "cadera"), que es el movimiento de caderas, haciendo juego con la falda y acentuando el movimiento hacia un costado; una variante de este llamado de avance, para desplazamiento en comparsa, marcando la cadera y un paso de una pierna hacia atrás; y por último, el paso tumbe que simula el 'caderazo', para tumbar al costado pero sin botarse. ${ }^{14}$

En las actuales comparsas los danzantes se despliegan organizados en bloques de bailarinas y bailarines en línea de cuatro personas, realizando los pasos en forma de espejo (grupos de dos bailarinas y su reflejo, otras dos bailarinas). El bloque de músicos va al centro y los bloques de bailarinas se ubican adelante y atrás. Los bailarines hombres tienen la particularidad de moverse y re-articularse como bloque, adelante o atrás. Generalmente los ellos cantan más las letras de las canciones, y las mujeres, solo bailan y marcan gritando "eh, eh, tumbe", con gestos enfáticos de las labores agrícolas danzadas. Quien ve pasar al ser performático del Tumbe carnaval, siente resonar los tambores que, a diversos toques los bloques de bailarinas, giran, pasean y juegan con sus faldas, caracterizando "escenas" de recolección de aceitunas, algodón o lavado de la ropa. Los hombres muestran sus brazos, simulan cortar caña agitando el machete (de utilería); acciones adornadas todas con cantos y movimientos centrados en las caderas, para avanzar en el desfile carnavalesco.

El Tumbe carnaval contemporáneo caló hondo en el sentir de la colectividad y más allá. Refleja un sentido y una relación con el territorio, una presencia arraigada en lo agrícola. No es azaroso que el colectivo tomara como decisión estético-sentimental vincular movimientos laborales y movimientos danzados; buscaban "poner esa práctica dentro de lo que es un ritmo" (Carolina Letelier).

Como señala Jackson, al considerar una fenomenología de la praxis corporal propone que

\footnotetext{
el carácter regular o convencional de estas prácticas corporales no es necesariamente el resultado de la obediencia a reglas o a intenciones conscientes, sino más bien una consecuencia de las maneras en que los cuerpos de la gente son modelados por hábitos infundidos dentro de un entorno compartido y articulados como movimientos. [...] estos patrones de uso del cuerpo son, en un sentido, neutrales, y pueden trasladarse de un dominio a otro (Jackson 2010: 71).
}

Ese tipo de articulaciones se hicieron al pasar movimientos de un contexto productivo agrícola a un contexto contemporáneo de desfile de carnaval urbano. Ese traslado de 'movimientos' revela no solo la interacción 


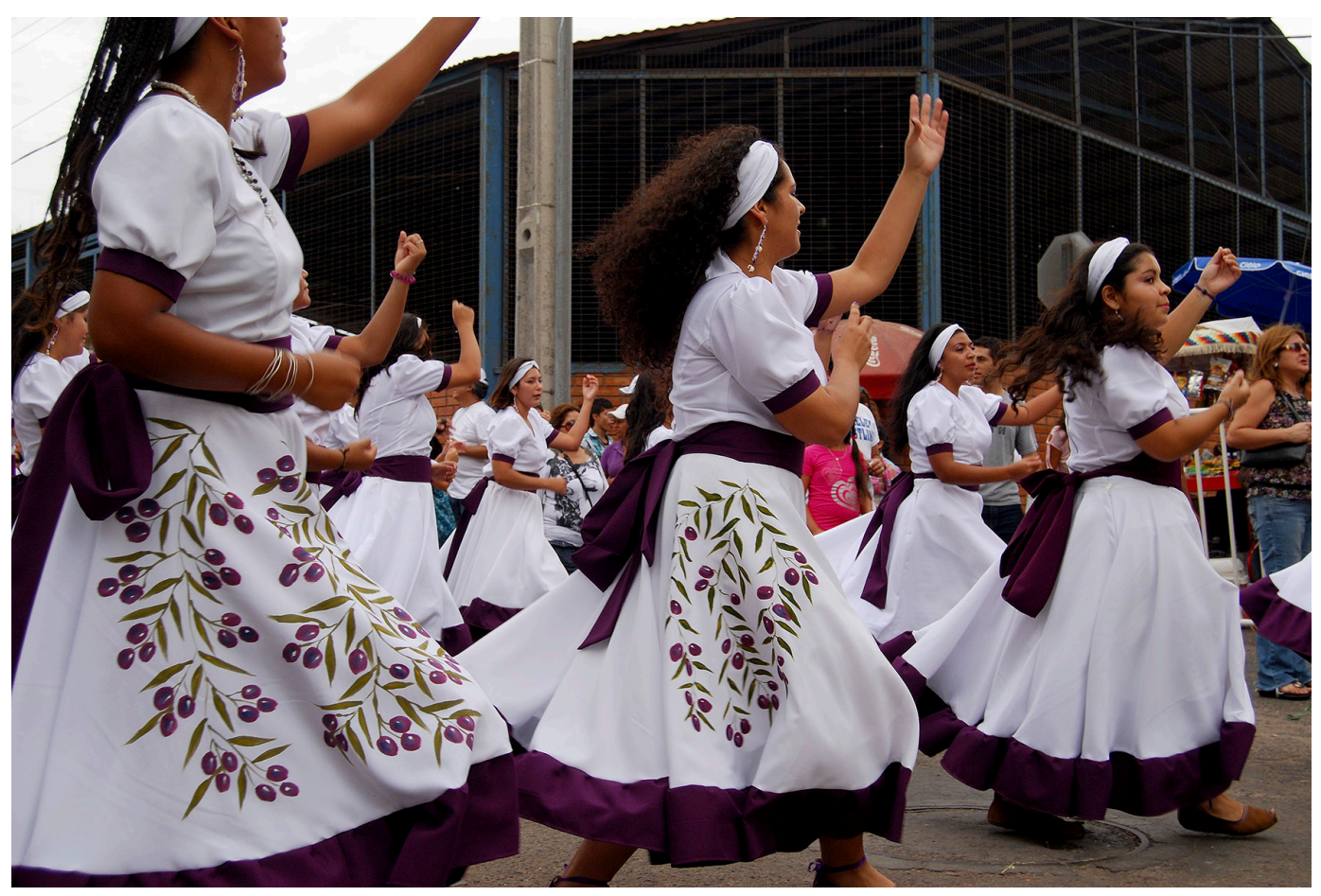

Figura 3. Paso de la raima o colecta de aceituna. Comparsa Oro Negro, enero 2012. (Fotografía: M. León). Figure 3. Step of the raima or olive collection. Oro Negro troupe, January 2012. (Photograph: M. León).

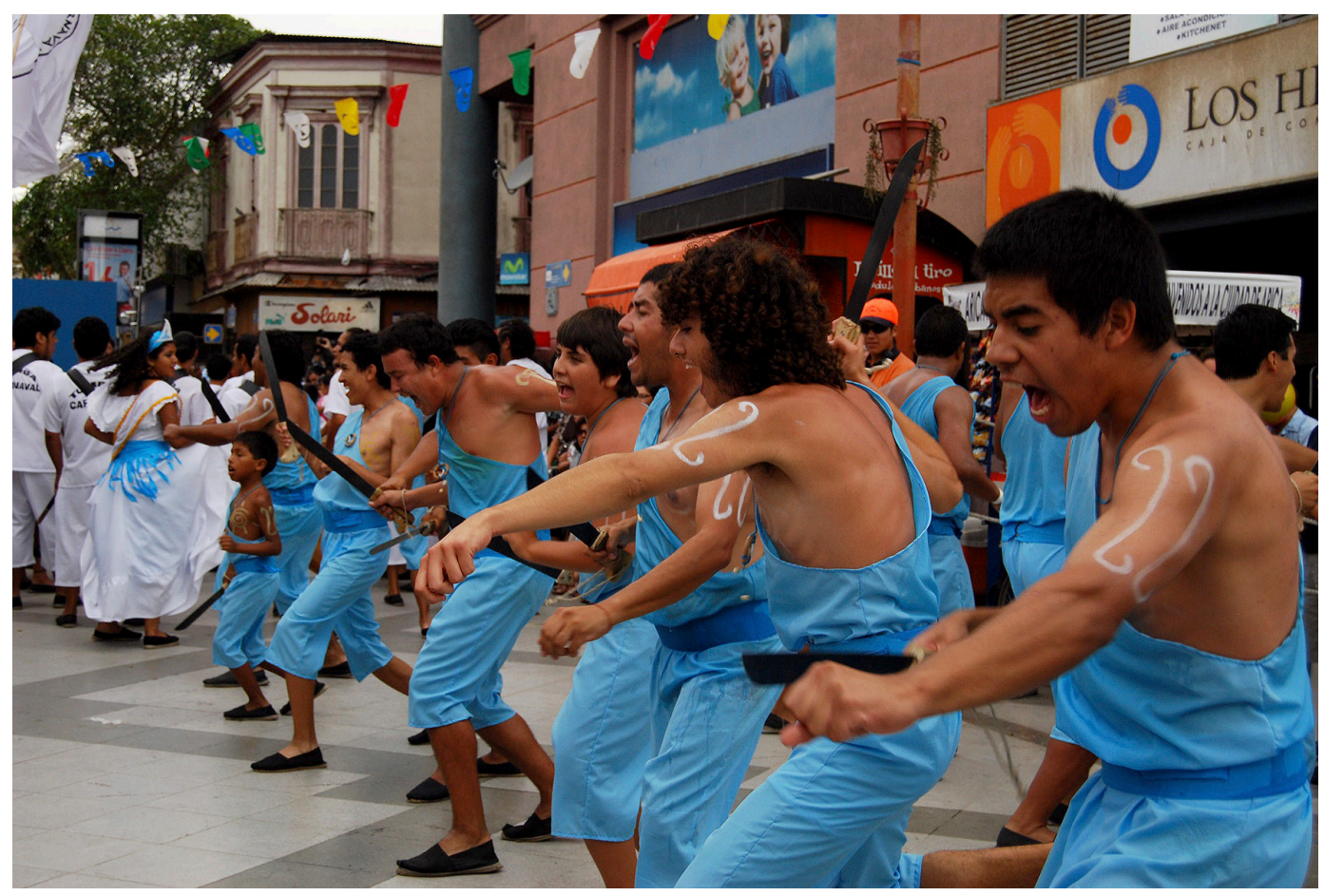

Figura 4. Secuencia "Paso de machete". Comparsa Tumbe Carnaval, enero 2012. (Fotografía: M. León). Figure 4. "Machete step” sequence. Tumbe Carnaval troupe, January 2012. (Photograph: M. León). 


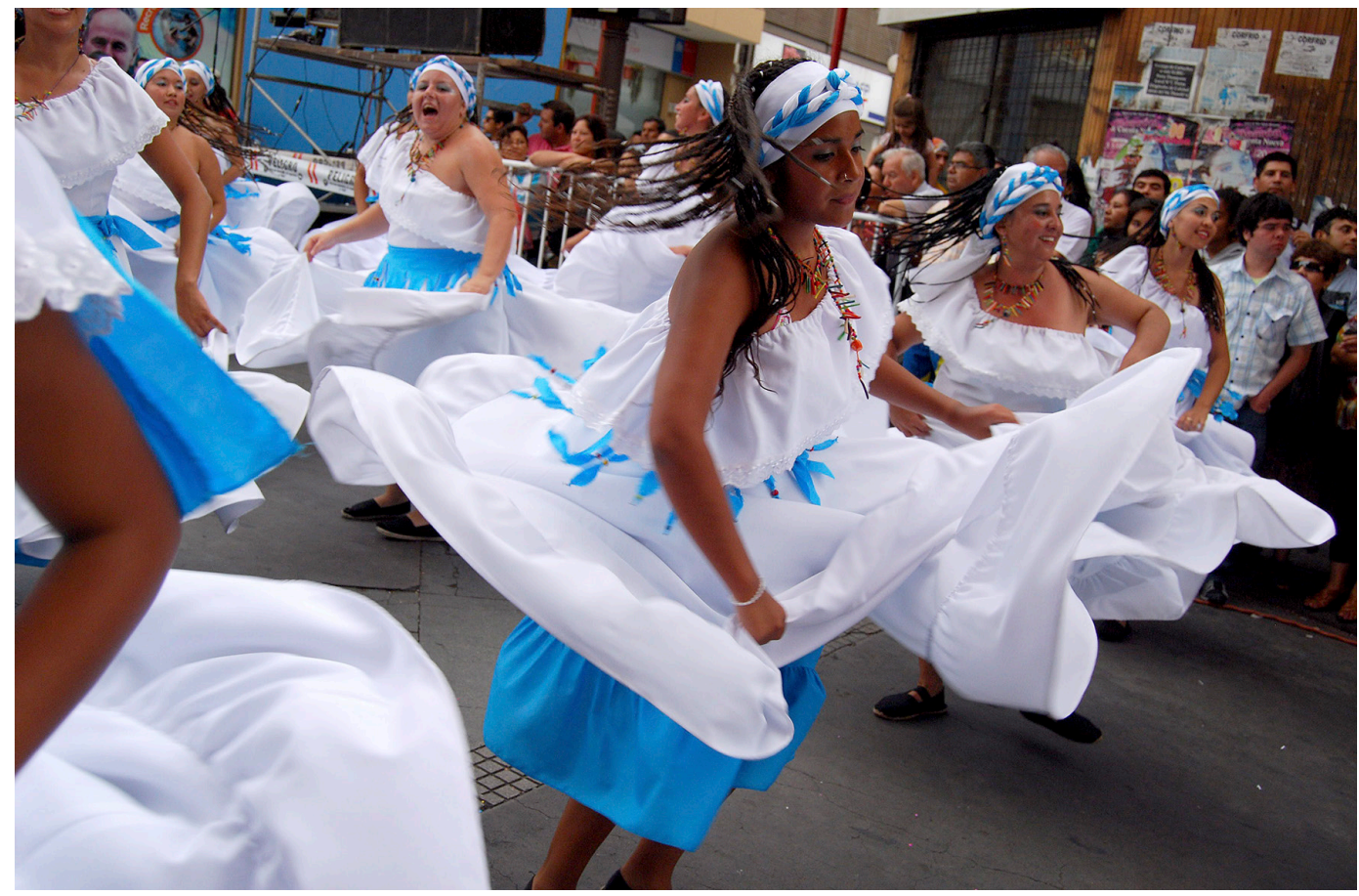

Figura 5. Secuencia: "Paso de avance", con giro de falda y "Avance". Comparsa Tumbe Carnaval, enero 2012. (Fotografía: M. León). Figure 5. Sequence: "Advance step", with a turn of the skirt and "Advance". Tumbe Carnaval troupe, January 2012. (Photograph: M. León).

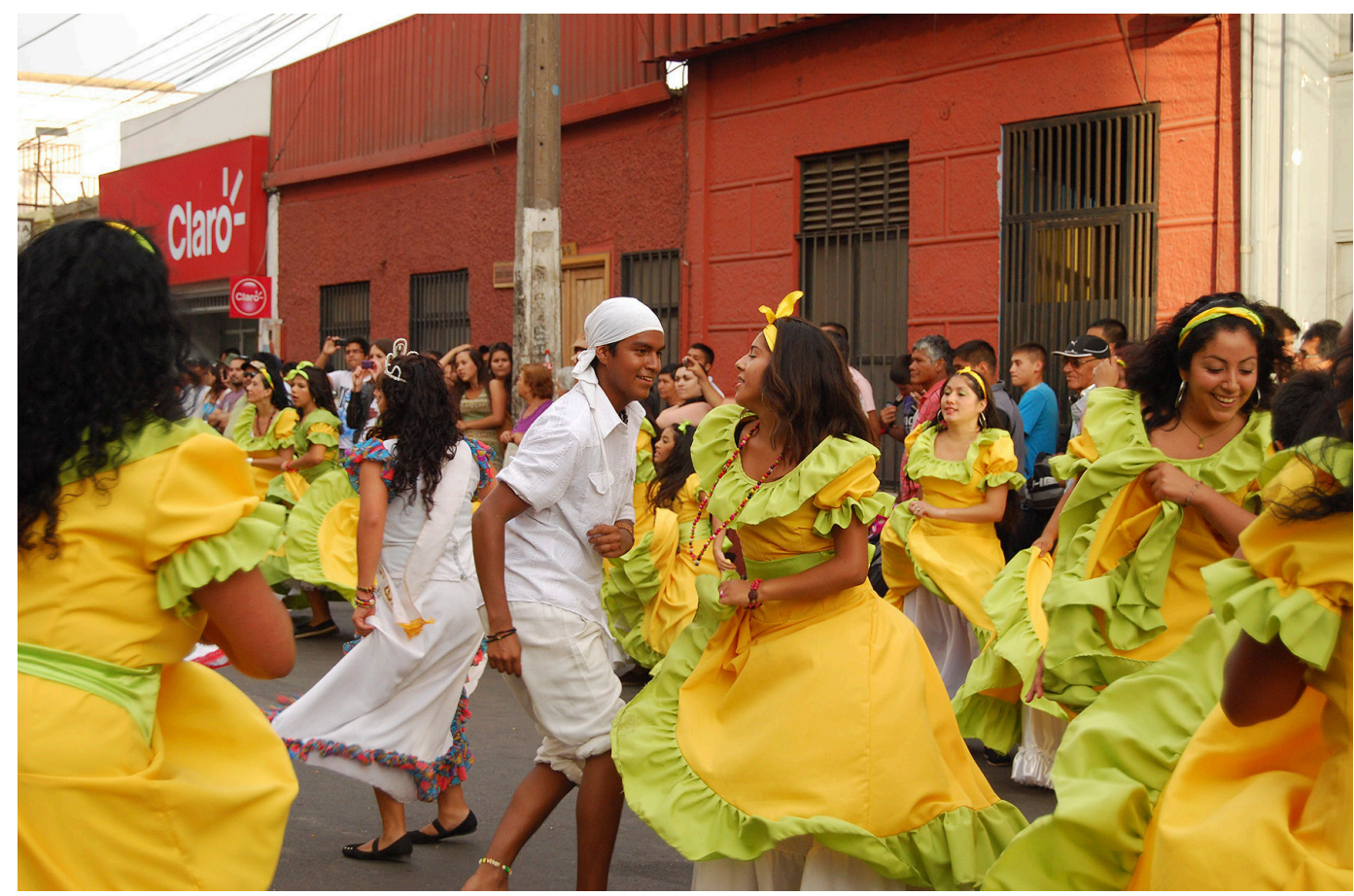

Figura 6. Juego de coqueteo entre parejas, simulando una ronda. Comparsa Arica Negro, enero 2012. (Fotografía: M. León). Figure 6. Flirting game among couples, simulating a circle. Arica Negro troupe, January 2012. (Photograph: M. León). 


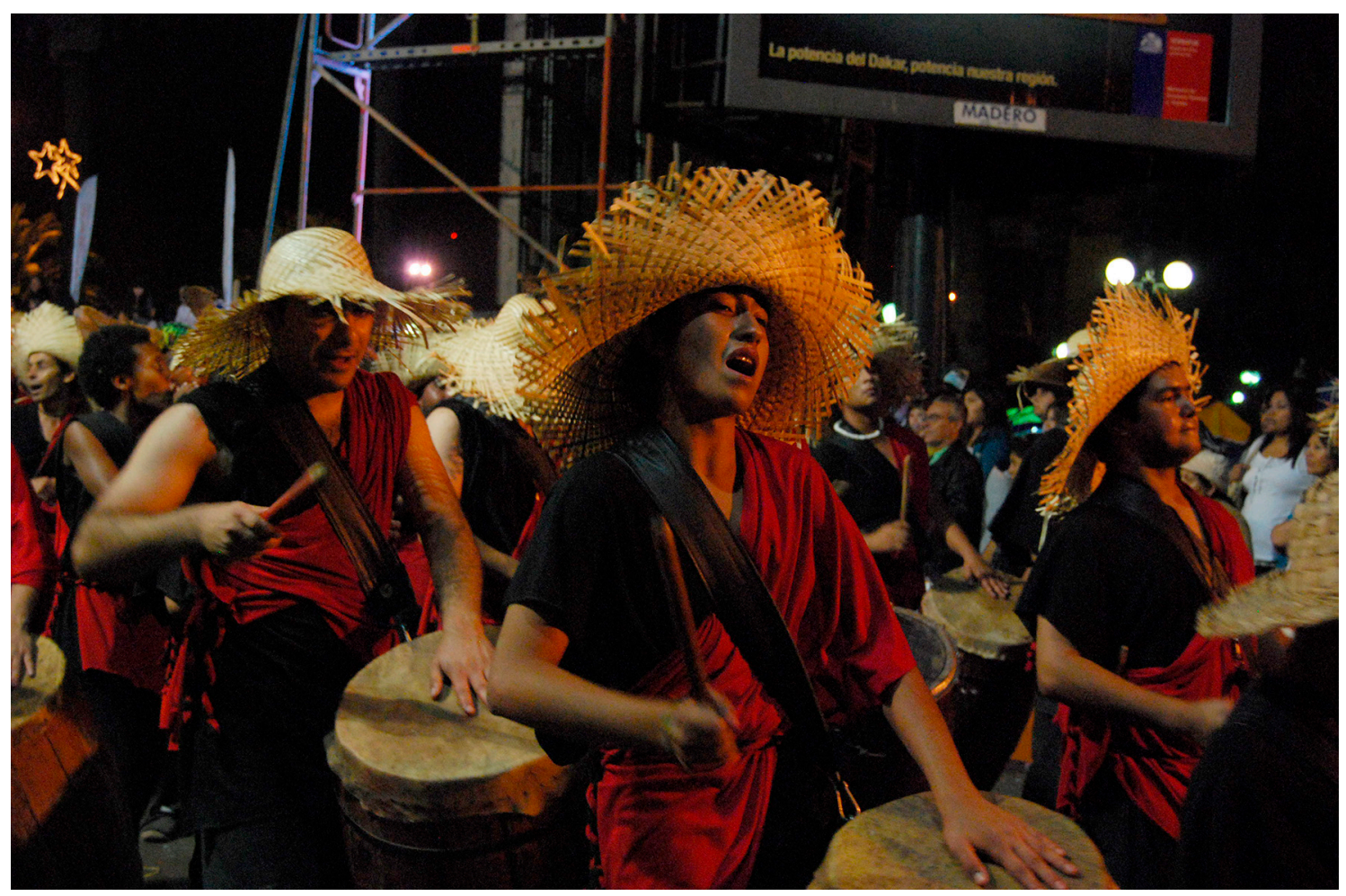

Figura 7. Los tambores de la comparsa Tumbe Carnaval, enero 2012. (Fotografía: M. León). Figure 7. Drummers of the Tumbe Carnaval troupe, January 2012. (Photograph: M. León).

de patrones habituales del uso del cuerpo, como un pasado que vuelve, sino un modo de comprender el mundo (Jackson 2010, Blacking 2007).

La acción colectiva de dar vida a la comparsa, bajo la denominación emic de recreación, expone con claridad el uso de elementos de memoria, como un archivo que levantaron y registraron los más antiguos de la comunidad. Esa oralidad fue la fuente para la comparsa; una suerte de documento vivo, operando la noción de distancia: registrar un tiempo que ya no existía; un baile y fiestas olvidadas. En esos relatos orales existen gestos, pasos, espacialidades, cantos y dimensiones de la performance, que Taylor (2011) denomina "repertorio" y que, por ser una memoria corporal, exige presencia: "La gente participa en la producción y reproducción del conocimiento al estar allí" (Taylor 2011: 14), siendo irreproducible en documentos de archivo, porque es una memoria alojada en el cuerpo. El caderazo, la rueda, cortar la caña, el percutir un barril, raimar, cosechar algodón, etc., son nominaciones que aluden a ese repertorio que nutre y cimienta el tumbe como performance, un modo de conocimiento desde el saber-hacer.
Con el tiempo nacieron nuevas comparsas y nuevos pasos (que no son objeto aquí), que denotan la importancia creativa de esta unidad y la adherencia, desde algo innato (pre-existente), en la misma corporalidad. "Era como acompañar ese proceso, ese proceso político, era la idea de la comparsa, acompañarlo, y siempre es como llamativo, y va... ¡Y no costó mucho tampoco!, porque las mujeres aquí bailan bien, siempre tuvieron como, o sea siempre estuvo eso como en la sangre, así que no costó mucho" (Gustavo del Canto, entrevista personal, 04-02-2012).

La comparsa, unidad organizada de personas que pone en acción la performance del Tumbe carnaval, como narración se desdobla en acción y presencia en las calles. La comunidad quería usar las calles "y nosotros queríamos básicamente rescatar lo que hablaba Wollman Cruz, cuadrillas de tambores, salir de la ciudad, volver a eso. Y decidimos utilizar y hacer casi como una analogía poética" (Gustavo del Canto, entrevista personal, 04-02-2012).

Conformada la comparsa, el Tumbe carnaval germinó. Como perfomance, su acción reiterada (de 


Yo-bailarina ejecutante
(en movimiento en un punto)

Figura 8. Esquema de la autora, extraído de cuaderno de campo (son solo algunos movimientos de pisos). Figure 8. Diagram by the author from her fieldwork notes (only some floor movements).

movimientos y pasos), de algo que se repite, pero renovado a la vez (Schechner 2003), ${ }^{15}$ se hace cuerpo al aprenderse haciendo: ensayos tras ensayos, un ciclo anual para consolidar una corporalidad bajo la conexión sonido-movimiento. Asimismo, los integrantes son afectados, no en un sentido emocional, sino de dejarse afectar, más allá de la representación (Goldman 2016: 113): un conocimiento desde lo sensible y vivenciando un sentir-pensar desde el cuerpo. Si bien los pasos son la construcción de un nuevo lenguaje cinético, de un repertorio de recuerdos y prácticas de los abuelos negros agricultores, el uso de este nuevo patrón de movimientos en un contexto alterado del cotidiano (desfile carnavalesco) induce al surgimiento de nuevas ideas. Las elaciones "habituales o 'fijadas' entre ideas, experiencias y prácticas del cuerpo pueden ser rotadas. Así, patrones alterados del uso del cuerpo pueden inducir a nuevas experiencias y provocar nuevas ideas" (Jackson 2010: 72).

Algo acontece en el ejecutante (músico/a o bailarín/a) a través de una experiencia no-verbal propia de la música-danza (Blacking 2013). La performance del Tumbe carnaval expone una narración de memoria: escenas de labores agrícolas. Que basada en la acción y la experiencia, permiten un cambio en mi percepción del yo y su colectividad. Asocio esto al hecho de que la ejecución del Tumbe carnaval en comparsa (organizada en líneas de cuatro bailarinas) tiene estructuración espacial -sin duda también temporal- de cuatro niveles de movimiento: "un "yo"-ejecutante; un desplazamientoindividual; la dualidad-espejo del "yo-tú" (otro); y la colectiva-cuerpo comparsa” (León 2017: 116). Intentaré explicar esto a continuación.

En el primer nivel, la persona (yo) adquiero/aprendo la ejecución del tumbe para moverme (como individualidad) y hacer los pasos acorde al ritmo y comunicación con el tambor (los cuatro pasos básicos). En el segundo nivel, ya asentada como ser-bailarina en el toque del tambor y su correspondiente movimiento de cadera, me permite usar los pasos y desplazarme ampliando el espacio. En el tercer nivel, ya no es solo ser-bailarina desplanzándome como individualidad, sino en juego con la dualidad de mi compañera (mi espejo), un otro, con quien reflejo esos pasos. En el cuarto nivel, como dualidad (yo-compañera) entretejidas en una relación 
sensible, amalgamadas, nos coordinamos como red de dualidades (cuatro bailarinas) en filas, movilizándonos como un todo danzante, como colectividad.

Distingo esos niveles (una separación analítica) desde mi propia experiencia en la práctica del conocimiento cinético de "hacer el tumbe" y corporizarlo. En los ensayos, varias bailarinas me expresaron esa sensible relación-comunicación que se genera con su compañera. Al bailar, en un lapsus, la individualidad se diluye y la experiencia sensoria se funde: te guía el tambor, mueves caderas, sonríes a la compañera, los brazos se alzan, el viento golpea, los chequerés y güiros se mezclan con los cantos de gaviotas, el atardecer se urde a los movimientos de las faldas; y ahí, donde no cabe el congelamiento de la racionalidad, se produce la apertura al sentir cinestésico como un todo, en que el tumbe (nos) modela en un nuevo espacio, ya que la performance posee elementos cognitivos, afectivos y volitivos, que solo se aprenden como experiencia vivida y trasciende lo racional, apuntando al orden de la experiencia común (Turner 2002: 119).

Los pasos del tumbe, como nuevos movimientos o patrones del uso del cuerpo, son mecanismos de memorización, que requieren de un proceso de dominio corporal, como lo deja ver Carolina al recordar a una compañera:

Inicialmente no participaba y luego empezó a meterse. Ella era bien tímida, empezó a meterse cada vez más, cada vez más, cada vez más; de bailar más o menos, pasó a bailar bien, y se metió en salsa, en otros tipos de baile, y hoy día también es una de las mejores bailarinas. A mi juicio ¡baila espectacular!, ¡baila espectacular!, ¿cachai? $\mathrm{Y}$ fue desarrollando ese tema, y que probablemente no lo hubiera desarrollado si no se hubiera encontrado con esto en el camino. Y ¡creo que fue "lo que nos pasó” ¡a varios!, por eso, es lo mismo auge" (Carolina Letelier, entrevista personal, 07-02-2013).

El "desarrollar el tema" es el aprendizaje de ese lenguaje contrastante propio de la performance, o sea, manejar la correspondencia sonido-movimiento (Feld 2008, Blacking 2014) para poder disfrutarlo y sentir. Pues el movimiento combina la experiencia sentida corporalmente con la organización de esa experiencia basada en patrones cognitivos que son culturalmente modelados, pues las formas de moverse también son formas de pensar (Sklar 2001: 4 en Buckland 2013: 149).

Los patrones de movimiento, y sustancialmente los pasos creados en los primeros años de la comparsa, deben ser comprendidos como un todo performático - universo cinestésico que incluye sonoridad, espacialidad y relación temporal-que propicia una conciencia colectiva gracias a los cuatro niveles espaciales de percepción corporal, indicados anteriormente. Esa conjunción de niveles construye un nuevo espacio, enfrentándose a la crisis de significación: ser afrochileno en un país donde no existían (León 2017: 125-126), y logra metas ocultas y desde sus materialidades comunicativas posibilita que la afrodescendiencia sea una experiencia.

Hay pleno consenso en que la gran mayoría de los afrodescendientes se autorreconocieron participando en la comparsa:

\begin{abstract}
Había mucha gente que, ¡siendo afro!, no tenía idea, no se reconocían, ¡incluso muchos que un día renegaron!, hoy día son líderes, hoy día son líderes... "Que, nooo... yo no soy negro, ique cómo se te ocurre!”. Entonces el proceso de investigación, de historia, de echar pa’atrás les hicieron un click; y si eso tú lo condimentai' con la cosa musical [... ¡engancho mucho más!; por eso, yo creo que hay un gran auge de las comparsas (Carolina Letelier, entrevista personal, 07-02-2013).
\end{abstract}

Algo ocurre, y esto es una conjunción teórico-práctica del cuerpo como experiencia concreta.

\begin{abstract}
Sí, esa es la verdad, muchas de las personas que llegan acá llegan por parte de la música, o en el caso de las chiquillas por el baile, en ningún momento se les pasa por la mente ¿a ver si soy afrodescendiente o no?, de verdad... muy pocas personas dicen "sí, parece que soy afrodescendiente", no tienen una noción concreta, no tienen una noción concreta; pero a través del tiempo las personas que ya tienen tiempo [...] han reconocido, o se han dado cuenta de que en sus propias familias sí hay o hubo un vestigio africano o de afrodescendiente (Ronald Vergara, entrevista personal, 02-02-2013).
\end{abstract}

Si bien varios integrantes que participaron de la primera comparsa tenían ya una conciencia eclipsada sobre su ascendencia negra -como Marta Salgado-, para otros, el proceso de aprehender el tumbe los llevó a reafirmar su afrodescendencia e incluso en quienes no tenían información de su origen familiar. Una vez existiendo este dispositivo artístico-sensible del Tumbe carnaval como un cuerpo-comparsa, las personas "enganchan", "desarrollan el tema", "hacen un click". Es el caso de Diego, quien no participó en la primera comparsa, al narrarme cómo conoce el tumbe en el desfile, ilustra ese conocimiento alojado en el cuerpo que se abre, desarrolla y permite incorporar nuevas ideas de presencia: 


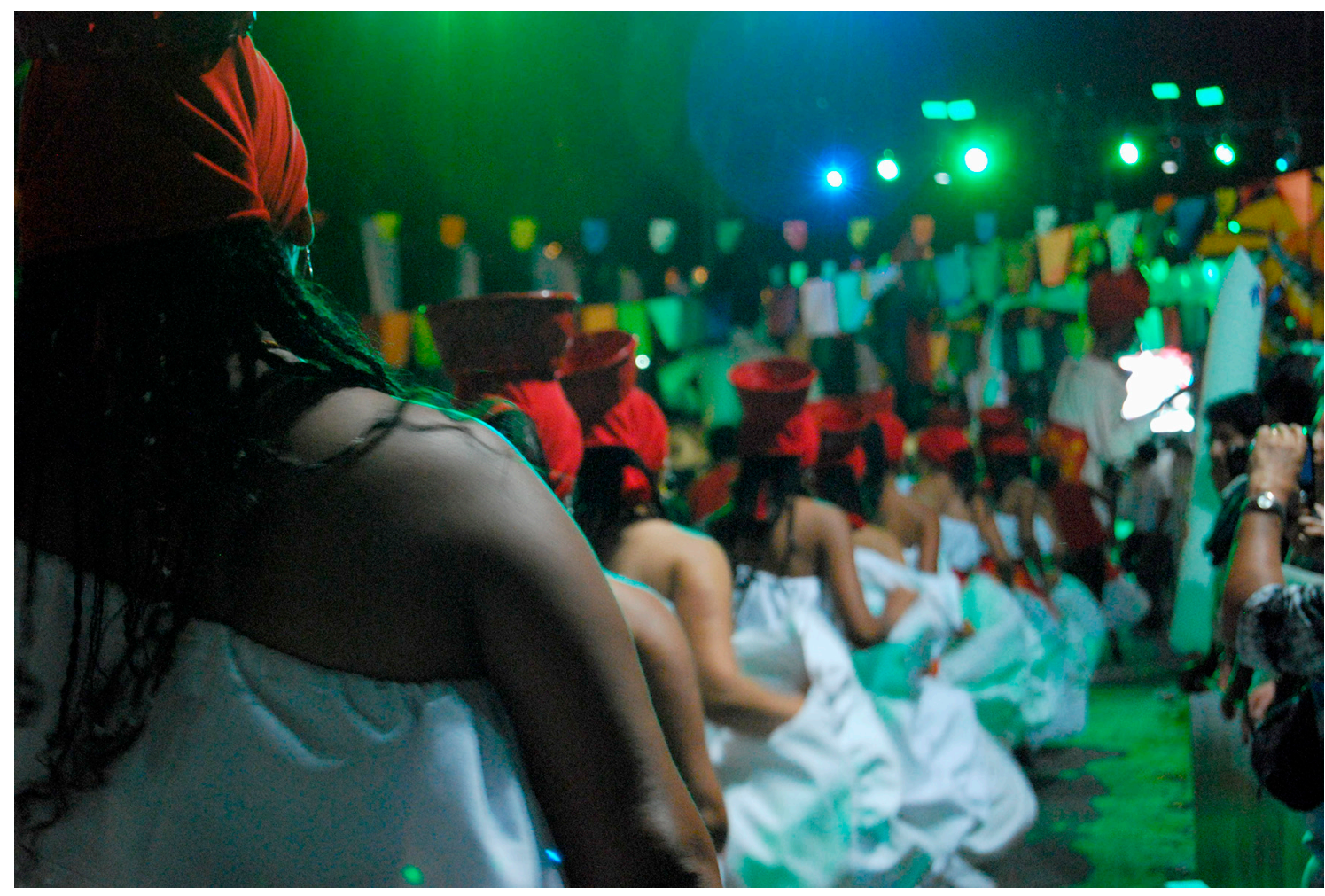

Figura 9. Bailarinas llegando al "Jurado", comparsa Tumbe Carnaval, enero 2012. (Fotografía: M. León). Figure 9. Female dancers approaching the "Jury", Tumbe Carnaval troupe, January 2012. (Photograph: M. León).

Entonces es fácil ¡entrar en ritmo en el carnaval! Porque es cuando la comparsa está como en su máxima expresión [...] y bueno los tambores, la percusión, también como que te llaman, te hacen entrar altiro, entonces no sé... eso me enganchó inmediatamente, entonces yo creo que es un poco eso, en la sangre, de la descendencia negra, porque hay gente que yo conozco, que nos toma inmediatamente [...] sí, sí po’... jal principio sí po’!, es lo que te engancha, pero ya después nosotros empezamos a conocer un poquito más, y claro yo empecé a buscar si tenía alguna, alguna ascendencia afro, ¿cachai?, porque al principio no sabía nada, pero después una vez que estuve adentro, ahí empecé averiguar, y sí po' tenía ascendencia, y bastante directa, y no tenía ni idea (Diego Marambio, entrevista personal, 29-11-2016).

\section{CONCLUSIONES}

La performance del Tumbe carnaval es una noción concreta de ser afroariqueño/afrochileno propiciada por la música-danza de un cuerpo colectivo: la comparsa. Siguiendo la musicología dialógica de Blacking, lo que interesa es estudiar las funciones cognitivas de la música y la danza, pues "o fazer musical pode ser uma ferramenta indispensável para a intensificação e a transformação da consciência como um primeiro passo para transformar as formas sociais" (Blacking 2014: 208), como sería el caso aquí observado.

La comunicación musical, como un lenguaje contrastante, posibilita que los símbolos musicales puedan ser transformados en otros símbolos y viceversa, sin la mediación de la convención social (Blacking 2014: 209). Así, el Tumbe carnaval se convirtió en un símbolo de lo afroariqueño/afrochileno. Sin embargo, va más allá de una abstracción simbólica o concepción idealista de cultura a nivel de la representación, porque esa comunicación musical la hacen y logran personas concretas desde un pensar-hacer, desde una producción de presencia (Gumbrecht 2010). Los pasos -desde la creatividad- unieron elementos aparentemente disociados, para una mirada idealista u racionalista, pues basados en los recuerdos fueron llevados a movimientos, al dejarse afectar por la sensibilidad (Favret 2005, Goldman 2016), identificando modos de usar el cuerpo asociados a un entorno y un 
espacio (Jackson 2010) en un universo agrícola en el cual los negros crearon y recrearon sus vidas.

La performance del Tumbe carnaval logra unir un pasado con un presente, desde la sensibilidad, enfrentando la violencia de la chilenización. El caso del Tumbe carnaval "rescatado" tiene así una función histórica: dar continuidad a una presencia negra o "afro" -con sus diversas nominaciones- en un territorio específico (León 2017: 76). Por ello, la creación del Tumbe carnaval contemporáneo en formato comparsa es un dispositivo de memoria que revela un modo de un saber-hacer de esa comunidad. Es la consolidación de un universo comunicativo cuya correspondencia entre sonido-movimiento dibuja/escenifica las labores de sus abuelos. A la vez, la experiencia individual de aprender esa correspondencia comunicativa del bailar-tocar (oír-sentir) es el tumbe que se colectiviza en el desfile de carnaval.

En ese contexto ritual, cada persona vive una experiencia individual y colectiva a la vez, que impulsa a abrir universos y nuevas ideas (de un yo, un otro y nosotros) insertas en la experiencia del tumbe. Los pasos o movimientos agitan las "conciencias" dando soporte al autorreconocimiento afrodescendiente, siendo en muchos casos más potente que el discurso reivindicativo expresado solo en palabras del Movimiento político formal. La experiencia sentida en la performance desde un individuo comprometido con un cuerpo colectivo, todos armonizando en movimientos, pasos, sonidos, espacialidades y tiempos, produce una "forma concreta" de ser afrodescendiente, restaura una presencia negada y proyecta un futuro en ese entorno que siempre los cobijó.

Agradecmientos a los Andes y su comunidad de afrodescendiente en Arica, en especial -en este texto- a Carolina Letelier Salgado, Ronald Vergara, Diego Marambio, Marta Salgado, Gustavo del Canto y a los tumberos/as que hicieron posible este ritmo cautivante. Asimismo, a la Beca PEC-PG/CNPQ del Gobierno de Brasil permitiéndome realizar mi maestría y concluir este trabajo.

\section{NOTAS}

${ }^{1}$ Titular del diario La Estrella de Arica, 6 de enero 2003.

${ }^{2}$ Aunque el 6 de enero es la Pascua de Negros, esa primera salida se realizó el domingo 5 de enero de 2003. Sin embargo, la comunidad registra ese hito como " 6 de enero del 2003".

${ }^{3}$ Me refiero por "primera comparsa" a la conformada en el 2003. Según la oralidad existieron hasta 1940 comparsas (sin esa nominación) urbanas de negros, pero dejaron de existir. De la "primera comparsa", al alero de la ONG Oro Negro, nacerán nuevas. En la actualidad (2019) existen 4 comparsas que bailan en el Carnaval de Arica y la "primera comparsa" se ha tornado un mito. Si dicha comparsa tenía unas 30 personas, las actuales tienen, en promedio, 200 a 300 (no todas afrodescendientes).

${ }^{4}$ Usaré la distinción nativa de "Movimiento" (con mayúscula) para referir a Movimiento político cultural por el reconocimiento afrodescendiente. Emplearé "movimiento" o "movimientos" para las coreografías o términos emic, llamado de "pasos".

${ }^{5}$ Algunas aclaraciones: la comunidad usa a veces coloquialmente el término "abuelos negros" para referirse a sus abuelos. Ellos son la fuente de su memoria y base para la producción de una presencia afrodescendiente en el territorio. Será, en su gran mayoría, la tercera generación, los nietos de estos abuelos, quienes realizan ese proceso de rescate. Pero la nominación "nietos" es una categoría ética, alusiva a reconocerlos (como nietos) frente al amor con que ellos hablan de "sus abuelos" (muchos ya muertos). Ahora, afrochilenos/ afroariqueños, la comunidad usa después del proceso de su auto-proclamación (2000-2003), con un tinte político, frente agentes como el "Estado". En contexto coloquial se emplea negro/a (notoriamente en las letras de las canciones) y tumbero/as a un ejecutante o persona que vive en el universo del Tumbe carnaval (que puede ser negro, afro, o no afro, pero sí tumbero). La fluidez de transitar entre estas nominaciones no solo revela la riqueza polisémica (donde la realidad es múltiple) en que la performance Tumbe carnaval participa de la conformación de una presencia afrodescendiente, sino también que las materialidades de la comunicación de estas nominaciones no son neutras.

${ }^{6}$ No considero la danza y la música como ámbitos separados. Cuando hablo de performance musical, comprendo que la danza es parte de ella. Por espacio no describo aspectos sonoros, rítmicos (León 2017).

${ }^{7}$ Esta reconfiguración es significativa. Al ubicarse en los valles y el puerto los negros fueron mayormente impactados cuando el Estado chileno tomó posesión de territorio. La gran presencia aymara en la ciudad es un proceso migratorio posterior. Con la declaración del Puerto Libre (1953) y las mejoras de los caminos, la población aymara boliviana y chilena del altiplano bajó a los valles y al puerto, instalaron negocios y se emplearon en labores agrícolas compartiendo territorio con las familias negras. Esa presencia aymara -desde 1940generó nuevas dinámicas culturales, entre ellas el nacimiento del Carnaval Arica Con la Fuerza del Sol (Chamorro 2013).

${ }^{8}$ III Conferencia mundial contra el racismo, la discriminación racial, la xenofobia y las formas conexas de intolerancia, conocido coloquialmente como "Durban". En la Conferen$c i a+5$ encararon a Ricardo Lagos, en ese entonces predisente de Chile, quien dijo que en el país no existían negros. Eso los impulsó a organizarse y adoptando el término "afrodescendiente" como una bandera de lucha. 
${ }^{9}$ Después de Durban (2001) iniciaron un "rescate" de sus memorias y tradiciones, las que tiene distintos niveles (o etapas), difíciles de diferenciar, pues nunca se ha detenido ese "rescate". Existe sí un primer momento, entre 2001 al 2003, en el cual las familias se unen en torno a un proyecto FonDART (2002-2003) para revivir una comparsa urbana, cuya primera salida fue en enero de 2003. Posteriormente nacerán nuevas agrupaciones, diversos trabajos y procesos de conformación de la memoria de modos cada vez más creativos.

${ }^{10}$ La ruta patrimonial "La Ruta del Esclavo", Ministerio de Bienes Nacionales (2008); la "prueba piloto" de población afrodescendiente, CELADE-CEPAL (2009); entrevistas en Programa Memoria Siglo xxi (Dibam 2010); reconocimiento del "Club de Adulto Mayor Julia Corvacho" como Tesoros Humanos Vivos (CNCA, 2011).

${ }^{11}$ El Instituto Nacional de Estadísticas (INE) niega incluir la categoría afrodescendiente en el censo del 2012. Tras aguerridas negociaciones realizan el estudio ECAFro (2014), contabilizando 8415 afrodescendientes, los que constituyen el 4,7\% del total de la región (INE 2014: 14). Este estudio será estratégico para las negociaciones que llevarán finalmente al reconocimiento en el Congreso del Pueblo Tribal Afrodescendiente en la Ley 21151 (2019).

${ }^{12}$ Las características más significativas para la percepción afrodescendiente según ECAFro son entre otros: apariencia física $(59,7 \%)$, los bailes que practica $(12,1 \%)$, apellidos que tiene (11,0\%) (INE 2014: 44), ubicando la danza como segunda categoría, reafirmando su valor. Entre los bailes, el Tumbe carnaval es el más practicado $(87,2 \%)$ por la comunidad (INE 2014: 61).

${ }^{13}$ En todos los registros culturales sobre este grupo mencionan al Tumbe carnaval. No es menor la difusión de las comparsas que representan lo 'afroariqueño', participando en Carnaval Mil Tambores (Valparaíso), Carnaval San Antonio de Padua (Santiago) y otros espacios artísticos, repercutiendo en la sociedad chilena. Además, la inclusión de un tumbe en el disco Cantos y músicas afrodescendientes en América Latina (CEspial \& Radio Nacional de Colombia, 2012) o en el montaje Me Niegan pero Existo (2013) de la Compañía El Palomar.

${ }^{14}$ Son los cuatro primeros pasos. Actualmente hay más de 21, combinados con distintos desplazamientos (pisos). Esto ante la necesidad de "avanzar en comparsa", a diferencia del tumbe de la tradición oral que no se desplazaba, sino que se bailaba en ronda.

${ }^{15}$ Enfatizó que el tumbe como performance, con su correspondencia sonido-movimiento, que se aprende y hace carne en la repetición de "hacer tumbe", pero siempre es algo nuevo a la vez. Schechner alude al fenómeno procesual de la performance, donde el Tumbe carnaval en el desfile pasa por: prefiguración, figuración, momento liminar, y salir del personaje (ya de modo liberado), que no detallo por espacio.

\section{REFERENCIAS}

ArtaL, N. 2012. A(f)rica: relatos y memorias afrodescendientes en Arica tras la chilenización y el conflicto entre Perú y Chile (1883-1929). Aletheia 2 (4).

BÁEz, C. 2010. Lumbanga: memorias orales de la cultura afrochilena. Arica: Herco.

BARDET, M. 2015. A filosofia da dança: um encontro entre dança e filosofia. São Paulo: Martins Fortes.

Blacking, J. 2007. Música, cultura y experiencia. Cadernos de Campo 16: 201-218.

BlACKing, J. 2013. Movimento e significado: a dança na perspectiva da antropologia social. In Antropologia de la Dança I, G. Guilhon, Org., pp. 75-86. Florianopolis: Insular.

Briones, V. 2004. Arica colonial: libertos y esclavos negros entre el Lumbanga y las Maytas. Chungara: 813-816.

BRIONES, V. 2013. Afrodescendencia y registros documentales coloniales para el corregimiento de Arica. In ... y llegaron con cadenas... Las poblaciones afrodescendientes en la historia de Arica y Tarapacá (siglos XVII-XIX), A. Díaz et al., Comps., pp. 79-125. Arica: Ediciones Universidad de Tarapacá.

BuCKLAND, T. 2013. Mudança de perspectiva na etnografia da dança. In Antropologia de la Dança I. G. Guilhon, Org., pp. 143-154. Florianopolis: Insular.

CAnto, G. 2003 Oro negro: una aproximación a la presencia de comunidades afrodescendientes en la ciudad de Arica y el Valle de Azapa. Santiago: Semblanza.

Celestino, O. 2004. Los afroandinos y "La ruta del esclavo". In Los afroandinos de los siglos XVI al XX, UNESCO, Ed., pp. 23-33. Lima: UNESCO.

Celestino, O. 2004. Relaciones incas-negros y sus resultados en el capac-negro y los negritos. In Los afroandinos de los siglos XVI al XX, UNEsco, Ed., pp. 34-58. Lima: UNESCO.

Cuche, D. 1975. Poder blanco y resistencia negra en el Perú: un estudio de la condición social del negro en el Perú después de la abolición de la esclavitud. Lima: Instituto Nacional de Cultura.

DíAz, A. 2014. La violencia del discurso: la problemática política y social de Tacna y Arica, a través de la prensa local 1918-1926. In Tiempos violentos. Fragmentos de historia social en Arica, A. Díaz et al., Comps., pp. 75-84. Arica: Ediciones Universidad de Tarapacá.

Díaz, A., Galdames, L. \& Ruz, R. Comps. 2013....y llegaron con cadenas... Las poblaciones afrodescendientes en la historia de Arica y Tarapacá (siglos XVII-XIX). Arica: Ediciones Universidad de Tarapacá.

Ducongé, G. 2015. Afro-ariqueños: rupturas, hibridismos y continuidades de un proceso de etnicidad. Tesis para optar el título de Magíster en Antropología, UCN-UTA, Arica, Chile.

EspinosA, M. 2013. Reconstrucción identitaria de los Afrochilenos de Arica y el Valle de Azapa. Memoria para optar el título de Antropóloga, Departamento de Antropología, Universidad Academia de Humanismo Cristiano, Santiago, Chile. 
Favret, J. 2005. Ser afetado. Cadernos de campo 13: 155-161. FeLD, S. 2008. El sonido como sistema simbólico: el tambor kaluli. In Las culturas musicales. Lecturas de etnomusicología, F. Curces, Coord., pp. 331-355. Madrid: Trotta.

GoldMAN, M. 2008. Os tambores do antropólogo: antropologia pós-Social e etnografía. Ponto Urbe. Revista do núcleo de antropología urbana da USP 2 (3).

Goldman, M. 2016. Jeanne Favret-Saada, os afetos, a etnografia. In Mais Alguma Antropologia, M. Goldman, Ed., pp. 111-118. Rio de Janeiro: Ponteio.

GonzÁlez, S. 1995. El poder del símbolo en la chilenización de Tarapacá: violencia y nacionalismo entre 1907 y 1950. Revista de Ciencias Sociales 5: 42-56.

GonzÁlez, S. 2008. La llave y el candado. El conflicto entre Perú y Chile por Tacna y Arica (1883-1929), Santiago: LOM.

Gumbrecht, H. 2010. Produção de presença. O que o sentido não consegue trasmitir. Rio de Janeiro: Contrapunto.

Новsвawm, E. Org. 2006. A invenção das tradições. Rio de Janeiro: Paz e Terra.

INE. 2014. Primera Encuesta de Caracterización de la Población Afrodescendiente de la Región de Arica y Parinacota. <http:// www.ine.cl/canales/chile_estadistico/estadisticas_sociales_culturales/etnias/pdf/Presentacion-ENCAFRO.pdf> [consultado: 10-09-2016].

JaCkson, M. 2010. Conocimiento del cuerpo. In Cuerpos plurales. Antropología de y desde los cuerpos, S. Citro, Coord., pp. 60-82. Buenos Aires: Biblos.

LEón, M. 2014. Tras un sonido afrodescendiente en Chile: elaboraciones y readecuaciones de la estructura sonora del tumba carnaval. In Memorias del IV Congreso Internacional Negritud. Estudios Afrolatinoamericanos, S. Valero, Ed., pp.163-176. Cartagena: Negritud \& Universidad de Cartagena.

LEón, M. 2016. Tempos múltiplos: experimentar a memória afroariqueña através da dança tumba carnaval. In Anais do II Seminário Pontos, Linhas e Nós: etnografia, artes e cidades, R. Gonçalves, M. León \& D. Cordeiro, Orgs., pp. 83-92. Niteroi: NARUA-Cosmopoliticas-Lepec-PPGAUniversidade Federal Fluminense.

LEÓN, M. 2017. "Los nietos de los abuelos negros...” A (re)criação da primeira comparsa de tumba carnaval. Performance, experiência e memória afrodescendente em Arica (Chile). Tesis para optar al título de Maestría en Antropología, Universidade Federal Fluminense, Niteroi, Brasil.

Letelier, C. 2015. ¡Soy Afroariqueña! Rufian 21. <https:// rufianrevista.org/portfolio/soy-afroariquena/> [consultado: 22-10-2020].

Massey, D. 2015. For space. London: Sage.

Mora, N. 2011. Afro-chilenos. Cultura e Política no ritmo tumbero. Tesis para optar al título de Maestría en Antropología, Universidade Federal Fluminense, Niteroi, Brasil.

Morong, G. 2014. De la historiografía nacional a la historiografía de los bordes. Violencia epistémica y emergencia de lo subalterno en el contexto de la chilenización del norte grande, siglos XIX-Xx. In Tiempos violentos. Fragmentos de historia social en Arica, A. Díaz, Ruz R. \& L. Galdames, Comps., pp. 11-22. Arica: Ediciones Universidad de Tarapacá. Ricoeur, P. 2004. La memoria, la historia y el olvido. Mexico City: Fondo de Cultura Económica.

Ruz, R. 2013. El Perú negro en magazines chilenos. Imagen y alteridad en la revista corre-vuela. 1910-1930.

SAlgado, M. 2015. Crónica del Movimiento Pueblo Afrochileno: la lucha por el reconocimiento constitucional. Kuriche. Perspectivas de la diáspora africana en Chile: 25-29. <https://rufianrevista.org/portfolio/cronica-delmovimiento-pueblo-afrochileno-la-lucha-por-el-reconocimiento-constitucional/> [consultado: 22-10-2020].

IN ...y llegaron con cadenas... Las poblaciones afrodescendientes en la Historia de Arica y Tarapacá (siglos XVII-XIX), A. Díaz, L. Galdames \& R. Ruz, Comps., pp. 229-252. Arica: Ediciones Universidad de Tarapacá.

SAHLINS, M. 2004. Adeus aos tristes tropos: a etnografía no contexto da moderna historia mundial. In Cultura na Pratica, M. Sahlins, pp. 503-534. Rio de Janeiro: UfRJ.

Salgado, M. 2010. El legado africano en Chile. In Conocimiento desde adentro. Los afrosudamericanos hablan de sus pueblos y sus historias, S. Walker, Comp., pp. 223-270. La Paz: Fundación Pedro Andavérez Peralta-Afrodiaspora Inc., -Fundación Interamericana-Fundación PIEB.

Salgado, M. 2013. Afrochilenos. Una historia oculta. Coquimbo: Centro Mohammed vi para el Diálogo de Civilizaciones.

SCHECHNER, R. 2003. O que é performance? O percevejo 12: 25-50.

SEeger, A. 2015a. Por que cantam os kĩsêdjê. Uma antropologia musical de um povo amazônico. São Paulo: Cosac Naify.

Seeger, A. 2015b. El oído etnográfico. In Sudamérica y sus mundos audibles. Cosmologías prácticas sonoras de los pueblos indígenas, B. Barbec de Mori, M. Lewy \& M. García, Eds., pp. 27-36. Berlin: Estudios Indiana 8.

Soto, J. \& Pizarro, E. 2014. A este cholo hay que matarlo como a un perro: violencia nacionalista y justicia en Arica durante los preparativos del plebiscito entre Chile y Perú (1925-1926), In Tiempos violentos. Fragmentos de historia social en Arica, A. Díaz, R. Ruz \& L. Galdames, Comps., pp. 85-100. Arica: Ediciones Universidad de Tarapacá.

Subsercaseaux, B. 2007. Historia de las ideas y de la cultura en Chile. Tomo Iv. Santiago: Universitaria.

TAYlor, D. Comp. 2011. Estudios avanzados de performance. Mexico City: Fondo de Cultura Económica.

Turner, V. 2002. La antropología del performance. In Antropología del ritual, GEIST, Comp., pp. 103-144. Mexico City: Instituto Nacional de Antropología e Historia.

Wormald, A. 1966 [1903]. El mestizo en el departamento de Arica. Anales de la Universidad del Norte 5: 183-318. 